\title{
Hand Hygiene Practices at Mina Hospitals’ Emergency Departments During Hajj Season 2012, Saudi Arabia
}

\author{
A. M. Al-Asmari, R. Nooh \\ Field Epidemiology Training Program (FETP), Ministry of Health, Kingdom of Saudi Arabia
}

\begin{abstract}
Introduction: Nosocomial infections are a critical problem affecting the quality of health care all over the world. A significant proportion of infections result from cross-contamination, by the hands of Health Care Workers (HCWs). Objectives: To observe and make recommendations for both the provided facilities and compliance of hand hygiene practices of HCWs at the emergency departments of the four Mina hospitals during Hajj 2012. Methods: An observational descriptive cross-sectional study. The observation includes the hand hygiene facilities in each department, and study participants were randomly selected from doctors and nurses in the emergency departments $(n=243)$ and were unobtrusively observed for "WHO 5 Moments". Results: Of total 243 doctors and nurses observed for hand hygiene compliance, the overall compliance rate was $45.5 \%$, hand hygiene adherence was lower among male than female HCWs, also male doctors were lower adherence than female doctors, and this was statistically significant. The high adherence was observed at moment after body fluid exposure risk (87.9\%). The favored way was alcohol hand rub at $77.4 \%$ (425), and also the provided facilities were significantly varied across hospitals. Conclusions: The overall hand hygiene compliance rate is $45.5 \%$. The compliance rate increases where there are available hand hygiene facilities.
\end{abstract}

Keywords: hand hygiene, hand washing, Hajj season, Saudi Arabia

Nosocomial infections are critical problems that affect the quality of health care. Patients admitted to the hospital are at risk of developing hospital-acquired infections. For more than a century, hand washing has been a universally accepted practice to reduce contact transmission of micro-organisms (Emmerson, Enstone, \& Griffin, 1996).

In addition, it is recognized as one of the few infection control practices with clearly demonstrated efficacy, and remains the cornerstone of efforts to reduce risk of infection. Besides isolation procedures, hand washing remains the simplest, least expensive, and most important measure to prevent transmission of nosocomial infections (Emmerson et al., 1996).

It was estimated that approximately two million hospital-acquired infections occurred in U.S. hospitals (Larson, MCGinely, Grove, Leyden, \& Talbot, 1986). This rate of infection is reported to be associated with 90,000 deaths (Larson et al., 1986).

The U.S. Institute of Medicine ranked health care associated infection in the top 10 of all causes of

Corresponding author: A. M. Al-Asmari, MD, principal investigator of Field Epidemiology Training Program (FETP), Ministry of Health, Kingdom of Saudi Arabia; research field: field epidemiology.

R. Nooh, Ph.D., general supervisor of Field Epidemiology Training Program (FETP), Ministry of Health, Kingdom of Saudi Arabia; research field: field epidemiology. 
death - the primary cause of $1 \%$ of deaths and major contributor to $3 \%$ of all deaths. These infections cost the U.S. health care system between $\$ 17$ million and $\$ 29$ billion (Larson et al., 1986).

Two major groups of microorganisms may be found on the skin: organisms that reside on it ("resident flora") and contaminants ("transient flora"). Unless introduced into body tissues by trauma or by medical devices such as intravenous catheters, the pathogenic potential of resident flora is usually regarded as low. In contrast, transient flora causes most nosocomial infections resulting from cross-transmission (Centers for Disease Control, 1988).

Prevention of bacterial contamination by transient flora and possible subsequent infection requires timely hand cleaning that may be achieved by washing or disinfecting the hands (Rotter \& Koller, 1991). There is no previous study to identify the hand hygiene practice which is the most effective way for the infection control in hospital and for safety of patients and Health Care Workers (HCWs) to not get infection when they are in hospital and in healthy, clean, and sterile environment.

\section{Literature Review}

Nosocomial infections have been recognized for more than a century as a critical problem affecting the quality of health care provided in hospitals.

Results of previous studies showed that at least one third of all nosocomial infections are preventable by optimal infection prevention programs (Haley et al., 1985).

Those infections affect over two million patients annually in the United States, causing substantial morbidity, contributing to mortality, and resulting in excess health care of $\$ 4.5$ billion (Larson et al., 1986). In the current era of managed care and diagnosis related groups (DRG), much of the economic cost of diagnosing and treating nosocomial infections is borne by hospital costing about $\$ 1.4$ million. Around the world, the rate of nosocomial infection ranges from $3 \%$ to $21 \%$ and the organisms causing these infections are reported to be transmitted by HCWs' hands contacts with patients (Anwar et al., 2009).

In the developed countries, about 5\%-10\% patients admitted to hospitals for acute condition develop infections when in hospitals (Madrazo et al., 2009). Infection-control programs have been demonstrated to reduce the rates of nosocomial infections and to be cost-effective (Haley et al., 1985). Infection prevention programs have resulted in reduction of infection rate of $32 \%$. Education program can improve hand hygiene practice by increasing knowledge, positive altitudes, and appropriate practice to result in compliance with international protocols and regulations for the prevention and control of nosocomial infections (Madrazo et al., 2009).

In a seminal intervention study 150 years ago, Semmelweis insisted that doctors performing autopsies washed their hands before delivering babies, reducing mortality due to streptococcal puerperal sepsis from $22 \%$ to 3\% (Centers for Disease Control, 1988).

Many studies since have confirmed that doctors washing their hands between seeing patients can reduce hospital infection rates (Rotter \& Koller, 1991).

In an extensive review of the literature published from 1879 through 1986, Larson et al. (1986) concluded that:

The collective evidence from non-experimental studies is very consistent with the hypothesis that hand washing is causally associated with a reduction in risk of infection. In fact, the evidence to that effect is probably as strong as it is for linking any other personnel practice with a patient outcome. (Larson et al., 1986) 
In the United States, the Centers for Disease Control and Prevention (CDC) and the Association for Professionals in Infection Control and Epidemiology (APIC) have published guidelines for hand washing (Centers for Disease Control, 1988). HCWs are reminded constantly by infection control practitioners and hospital epidemiologists of the importance of hand washing. At their 1995 annual meeting, the American Medical Association "reminded physicians that they have a professional obligation to wash their hands with an antiseptic before and between each patient encounter" (Rotter \& Koller, 1991).

Bartzokas, Williams, and Slade (1995) observed that, despite frequent patient contacts, senior doctors washed their hands only twice during 21 hours of ward rounds. Though doctors spend less time than nurses in direct patient contact and may think that they need to wash their hands less often, they have many transient contacts and move from ward to ward. The same is true for phlebotomists, physiotherapists, radiographers, and various technicians (Larson et al., 1986).

Self-reporting overestimates compliance with hand hygiene among HCWs. After unobtrusive observation of doctors to obtain a baseline hand-washing rate, Tibballs (1996) asked a sample to estimate their own hand washing rates before patient contact. Their average perceived rate of $73 \%$ (range $50 \%-95 \%$ ) contrasted sharply with the observed frequency of just 9\% (Centers for Disease Control, 1988). Pritchard and Raper were astonished that "doctors can be so extraordinarily self-delusional about their behavior" (Rotter \& Koller, 1991).

Although a significant proportion of infections result from cross-contamination, transmission of microorganisms from the hands of HCWs is considered as the main route of spread (Larson et al., 1986). Yet, health care workers still fail to wash their hands and fail to appreciate the importance of doing so (Rotter \& Koller, 1991). As hand hygiene is considered as a primary prevention method of transmission of infection in health care, a number of hand hygiene practice methods assessment has been put forward for evaluating and monitoring the effectiveness of interventions to hand hygiene (Larson, Aiello, \& Cimiotti, 2004).

Direct observation is a "gold standard" and frequently used method. It has two disadvantages: Firstly, it is extremely expensive, time-consuming, and resource-intensive; secondly, there is evidence from studies conducted among the public that those who are aware that they are being observed change their behavior significantly and are more likely to wash their hands (Larson et al., 2004).

Other methods like self-report, video monitoring, and microbiological methods are also used (Larson et al., 2004). Self-reporting method to measure hand hygiene practice by questionnaires or interviews is subjected to recall bias (Larson et al., 2004). Video monitoring is used when large space can be viewed at once (for example in ICU) but have disadvantages of privacy of patient and staff (Larson et al., 2004). Microbiological method is used for screening in society setting where less care of hand hygiene is required. However, in environments, such as hospitals where have higher level hygiene, microbiological methods are not appropriate because there is no significant difference between pre and post hand hygiene in these clean environments (Larson et al., 2004).

\section{Background}

Hajj is the fifth pillar of Islam and occurs once a year. It is mandatory for every Muslim who is financially capable to do it once in his life time. Every year, about two million people arrive to Mecca, Saudi Arabia, from about 183 countries to do their religious duties. These hajjis spend most of their Hajj duty at an area named Mina (also known as the Tent City), which is a neighborhood of Makkah Province, situated five kilometers to the east of the Holy City. It stands on the road from Mecca's city centre to the Hill of Arafat, and covers an area 
of approximately $20 \mathrm{~km}^{2}$. Hajjis usually spend their first night in the Valley of Mina. This ritual occurs from the eighth to twelfth day of Hajj. During that time, hajjis remain within strict constraints in terms of space and time, which may lead to overcrowding and transmission of disease.

Most hajjis seek medical care at Ministry of Health (MOH) facilities in Mina, whether Primary Health Care Centers or hospitals. There are four MOH hospitals in Mina. The first is Mina Al Wadi which contains 160 beds, the emergency department has 55 beds, and the total number of medical workers is 101: 67 nurses and 34 doctors. The second is Mina Aljaser with 150 beds, and the emergency department has 24 beds, with a total number of medical workers of 59: 30 nurses and 29 doctors. The third is Mina Altware, with 190 beds and the emergency department has 67 beds, with a total number of medical workers of 92: 58 nurses and 34 doctors. The fourth is Mina Alshara al jaded which has 50 beds, the emergency department has 18 beds, and total number of medical workers is 36: 30 nurses and 6 doctors. These four hospitals have a total bed capacity between 550-569 beds, with an estimated number of HCWs about 400-500 individuals at each hospital, with a total average number of HCWs about 1,800 .

\section{Aim of Study}

To explore hand hygiene practices of HCWs at emergency departments of the four Mina hospitals during Hajj season of 2012.

\section{Objectives}

(1) To observe the provided facilities for hand hygiene at each emergency department of the four Mina hospitals during Hajj season of 2012;

(2) To examine hand hygiene practices of doctors and nurses working at the emergency departments of the four Mina hospitals during Hajj season of 2012;

(3) To make recommendations with regard to hand washing facilities and practices of HCWs at the emergency departments of the four Mina hospitals during Hajj.

\section{Materials and Methods}

\section{Study Design}

A cross-sectional study was conducted to achieve the objectives. This study was conducted by unobtrusive observation without the knowledge of HCWs at the emergency departments of the four hospitals. The nurses and doctors were observed over two working shifts, each shift was 12 hours in duration. The observations were distributed equally over two days $(10 \& 11$ Thul Hijjah $1433 \mathrm{H})$. Structured observation sessions were performed at random across day/night shifts.

Each HCW was observed for five sessions. A single nurse or doctor was observed for at least five moments as possible during the same day. The moment and task completed were noted, the moment was not necessarily being related to the number of patients who were observed, such that the five moments may have been observed in five patients or in just one patient.

The observation period started when the nurse or doctor approached the patient whether he/she cleaned his or her hands prior to patient contact, and ended when either: (1) The nurse or doctor proceeded to clean his/her hands again; or (2) a coherent episode of care was completed as determined by the observer. We also documented the method and type of patient care. 


\section{Study Population}

The study was carried out on the nurses and doctors who worked at the emergency departments of the four Mina hospitals over the two-day period of 10 to $11 \backslash 12 \backslash 1433 \mathrm{H}$.

Each participant was selected randomly, one or two for every single hour of work shift at each emergency department of the four Mina hospitals. That meant about 120 participants in 24 hours (day) and was observed for five moments. That meant that in a day 600 moments were observed. As the study was carried out over a period of two days, this gave total moments observed as 1,215 moments.

We noticed the type of patient care participant doing it for patient and the action done by participant in that moment. When the action is carried out (positive action), it can be done in two ways: by rub hands with an alcoholic disinfectant or by washing them with soap and water. The absence of the action (negative action) is considered as such when prior instructions have been given to carry out an action which has not occurred.

\section{Instruments of Measurement}

Each HCW selected was evaluated by direct observation, non-participating and structured, by a neutral professional with prior training, who is familiar with the concept of the "WHO 5 Moments" of hand hygiene.

Observer training was done through practical examples of the five moments and demonstrating the WHO video on hand hygiene until deemed satisfactory by the researchers.

\section{Data Collection}

We used two questionnaires for this study. The first was the WHO form (Appendix A) which was filled once for each hospital to observe the facilities of each emergency department, in terms of number of beds, sinks, and other equipment for hand hygiene.

The second questionnaire was the Hand Hygiene Observation Tool (HHOT) prepared and developed at the Royal Free and University College Medical School, UCL (University College London) Research Department of Infection and Population Health to study the compliance of doctors and nurses practices and type of patient care activity (Appendix B).

\section{Statistical Analysis}

All data entered into a computer and were analyzed using EPI Info (version 3.5.3) and SPSS (version 20) respectively. Descriptive analysis was performed in line with study objectives. Using chi square test for male vs. female, doctors vs. nurses, etc. when considering hand hygiene.

Calculating hand hygiene compliance:

Hand hygiene compliance is calculated by dividing the number of times that hands were cleaned by the number of times that hands should have been cleaned.

$$
\frac{\text { Hand hygiene actions }}{\text { Hand hygiene opportunities }} \times 100 \%=
$$

\section{Results}

The sample consisted of 243 HCWs selected from emergency departments of four hospitals in Mina during Hajj $1433 \mathrm{H}$. The number of female and male HCWs was nearly equal (50.2\% females and 49.8\% males). Most of the emergency department HCWs were: nurses 139 (57.4\%) and doctors 103 (42.6\%).

Almost a third $(\mathrm{n}=80$ or $32.9 \%)$ of the participants were from Mina Al Wadi Hospital, $37.5 \%(\mathrm{n}=30)$ were doctors and $62.5 \%(n=50)$ were nurses; $55.0 \%(n=44)$ were males and $45.0 \%(n=36)$ were females. At 
Altware Hospital $(\mathrm{n}=74,30.5 \%), 48.6 \%(\mathrm{n}=36)$ were doctors and $51.4 \%(\mathrm{n}=38)$ were nurses; $52.7 \%(\mathrm{n}=39)$ were females and $47.3 \%(n=35)$ were males. At Aljaser Hospital $(n=56$ or $23 \%), 46.4 \%(n=26)$ were doctors and 53.6\% $(\mathrm{n}=30)$ were nurses; and the number of males and females were equal $(50.0 \%)(\mathrm{n}=28)$. At Alshara $(n=33$ or $13.6 \%), 33.3 \%(n=11)$ were doctors and $66.7 \%(n=22)$ were nurses; $54.5 \%(n=18)$ were females and $45.5 \%(n=15)$ were males (see Table 2$)$.

Regarding issues related to practicing hand hygiene, we found that the number of beds at emergency departments in the four Mina hospitals was as follows (see Table 1):

Table 1

The Number of Beds at Emergency Departments in the Four Mina Hospitals

\begin{tabular}{llll}
\hline Name of hospital & Number of beds & Name of hospital & Number of beds \\
\hline Al Wadi & 55 & Alshara & 18 \\
Aljaser & 24 & Altware & 18 \\
\hline
\end{tabular}

Table 2

Descriptive Data for HCWs at Emergency Departments of Mina Hospitals, Hajj 1433 H ( $n=243)$

\begin{tabular}{|c|c|c|c|c|c|c|c|c|c|c|}
\hline & \multicolumn{2}{|c|}{$\begin{array}{c}\text { Al Wadi } \\
(\text { no. of beds }=55) \\
(\mathrm{n}=80)\end{array}$} & \multicolumn{2}{|c|}{$\begin{array}{c}\text { Aljaser } \\
(\text { no. of beds }=24) \\
(\mathrm{n}=56)\end{array}$} & \multicolumn{2}{|c|}{$\begin{array}{c}\text { Altware } \\
(\text { no. of beds }=18) \\
(\mathrm{n}=74)\end{array}$} & \multicolumn{2}{|c|}{$\begin{array}{c}\text { Alshara } \\
(\text { no. of beds }=18) \\
(\mathrm{n}=33)\end{array}$} & \multicolumn{2}{|c|}{ Total } \\
\hline & No. & $\%$ & No. & $\%$ & No. & $\%$ & No. & $\%$ & No. & $\%$ \\
\hline \multicolumn{11}{|c|}{ Participants } \\
\hline Doctor & 30 & 37.5 & 26 & 46.4 & 36 & 48.6 & 11 & 33.3 & 103 & 42.4 \\
\hline Nurse & 50 & 62.5 & 30 & 53.6 & 38 & 51.4 & 22 & 66.7 & 140 & 57.6 \\
\hline \multicolumn{11}{|l|}{ Gender } \\
\hline Male & 44 & 55 & 28 & 50 & 35 & 47.3 & 15 & 45.5 & 122 & 50.2 \\
\hline Female & 36 & 45 & 28 & 50 & 39 & 52.7 & 18 & 54.5 & 121 & 49.8 \\
\hline
\end{tabular}

Concerning the number of sinks at emergency departments of the four Mina hospitals, we found that there were four sinks at Al Wadi Hospital emergency department and six sinks at Altware. The location of the sinks at both hospitals was inside patient examination rooms. Also, at both hospitals, there was liquid soap for cleaning, but was available at some sinks, not all. At both hospitals, HCWs used disposable paper for hand drying (see Table 3).

Table 3

Descriptive Statistics for the Independent Variables of the Study

\begin{tabular}{|c|c|c|c|c|c|c|c|c|}
\hline & $\begin{array}{l}\text { Number of } \\
\text { beds }\end{array}$ & $\begin{array}{l}\text { Number of } \\
\text { sinks }\end{array}$ & $\begin{array}{l}\text { Location of } \\
\text { sink in ward }\end{array}$ & $\begin{array}{l}\text { Items } \\
\text { available at } \\
\text { each sink }\end{array}$ & Available at & $\begin{array}{l}\text { Hand } \\
\text { drying by }\end{array}$ & $\begin{array}{l}\text { AHR } \\
\text { available at }\end{array}$ & $\begin{array}{l}\text { Hand hygiene } \\
\text { posters } \\
\text { available }\end{array}$ \\
\hline Al Wadi & 55 & 4 & Inside room & Liquid soap & $\begin{array}{l}\text { Some parts of } \\
\text { department }\end{array}$ & $\begin{array}{l}\text { Single use } \\
\text { paper }\end{array}$ & $\begin{array}{l}\text { Some parts of } \\
\text { department }\end{array}$ & All \\
\hline Aljaser & 24 & 0 & - & - & - & & All & All \\
\hline Alshara & 18 & 0 & - & - & - & & $\begin{array}{l}\text { Some parts of } \\
\text { department }\end{array}$ & All \\
\hline Altware & 18 & 6 & Inside room & Liquid soap & $\begin{array}{l}\text { Some parts of } \\
\text { department }\end{array}$ & $\begin{array}{l}\text { Single use } \\
\text { paper }\end{array}$ & All & $\begin{array}{l}\text { Some parts of } \\
\text { department }\end{array}$ \\
\hline Total & 115 & 10 & & & & & & \\
\hline
\end{tabular}

As regards to availability of alcohol hand rub (AHR) at emergency departments, AHR was available abundantly at both Altware and Aljaser hospitals, but only at some sites at Al Wadi and Alshara hospitals. 
Hand hygiene posters were completely available at Al Wadi, Aljaser, and Alshara hospitals, but at Altware Hospital, they were available at some sites only (see Table 3).

Overall, 1,215 opportunities for hand hygiene were observed, with an average adherence of $45.2 \%$ (see Figure 1). Adherence was less than 50\% at all hospitals, except for Altware Hospital which recorded the highest adherence to hand hygiene 64.1\%. Al Wadi Hospital recorded the lowest adherence (30.8\%) (see Figure 1).

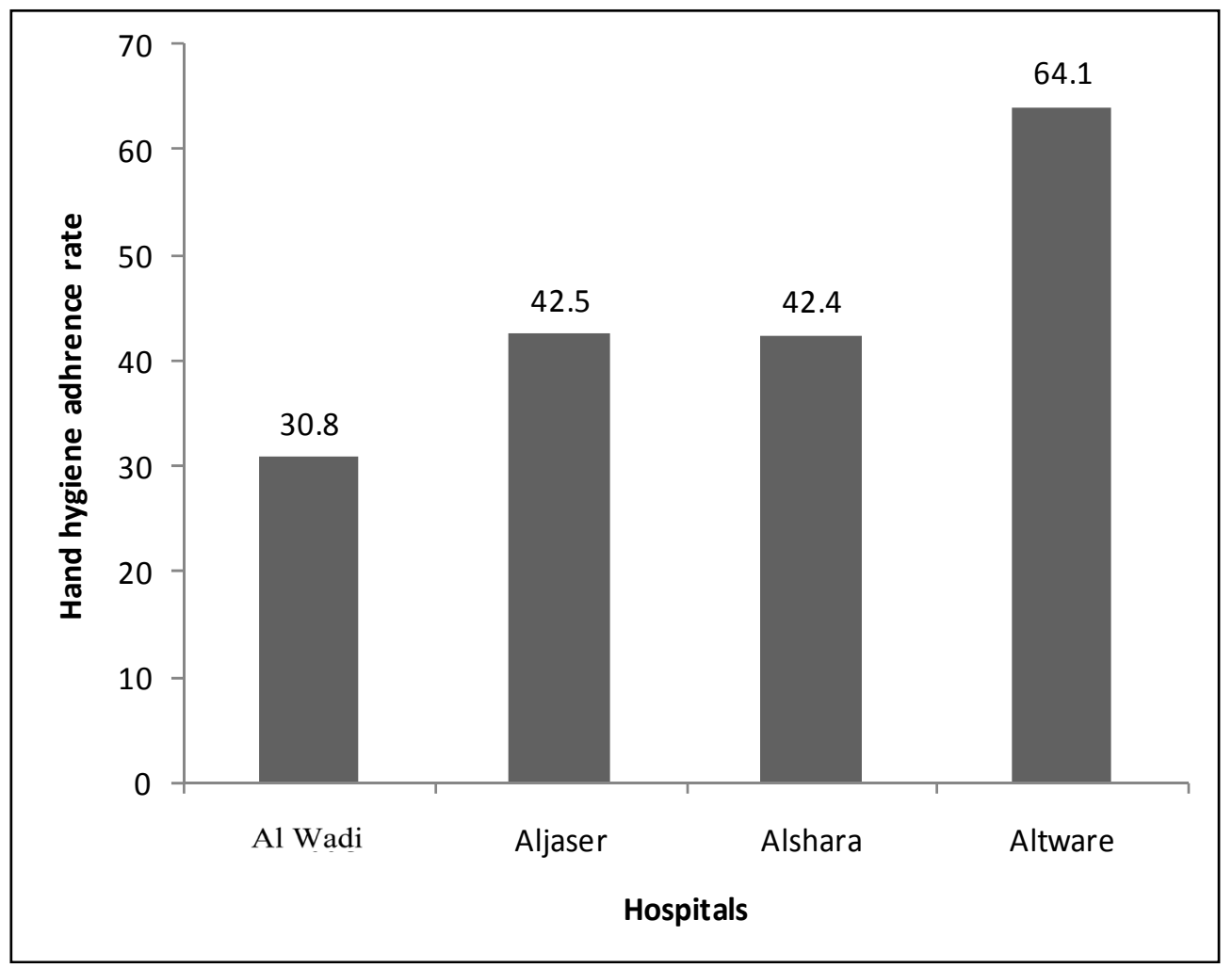

Figure 1. Hand hygiene adherence by hospital.

Chi-square analyses demonstrated that adherence rate was significantly different among hospitals $(P<$ 0.001). The lower rate of adherence was at Al Wadi Hospital ( $0 \%$ to $19 \%)$ and highest rate was at Altware Hospital ( $80 \%$ to $100 \%)$.

Adherence among the different categories of HCWs at emergency departments of the four Mina hospitals was $45.8 \%$ among doctors, and $45.3 \%$ among nurses (see Table 4). Physicians appeared to adhere more often to hand hygiene than nurses but the difference was not significant. Adherence to hand hygiene was lower in males than females, and the difference was statistically significant (see Table 5).

Table 4

Hand Hygiene Adherence by Healthcare Worker Category (Job)

\begin{tabular}{llllll}
\hline $\begin{array}{l}\text { Healthcare worker } \\
\text { category }\end{array}$ & $\begin{array}{l}\text { Hand hygiene } \\
\text { opportunities }\end{array}$ & $\begin{array}{l}\text { Hand hygiene } \\
\text { actions }\end{array}$ & Percent adherence & T value & P value \\
\hline Doctor & 515 & 236 & $45.8 \%$ & 0.129 & 0.897 (ns) \\
Nurse & 700 & 317 & $45.3 \%$ & & \\
\hline
\end{tabular}

Note. $P>0.05$ (chi-square); $\mathrm{ns}=$ not significant. 
Table 5

Hand Hygiene Adherence by Gender

\begin{tabular}{llllll}
\hline $\begin{array}{l}\text { Healthcare worker } \\
\text { category }\end{array}$ & $\begin{array}{l}\text { Hand hygiene } \\
\text { opportunities }\end{array}$ & $\begin{array}{l}\text { Hand hygiene } \\
\text { actions }\end{array}$ & Average adherence & T value & P value \\
\hline Male & 610 & 234 & 40.7 & 2.345 & $0.020^{*}$ \\
Female & 605 & 315 & 50.4 & & \\
\hline
\end{tabular}

Note. ${ }^{*}$ Significant at level 0.05 .

Figure 2 shows the adherence percentages among the different categories of HCWs at emergency departments of the four Mina hospitals. Nurses were more adhered to hand hygiene than doctors at Al Wadi and Altware hospitals (nurses $34.8 \% \& 70.0 \%$ and doctors $25.3 \% \& 57.8 \%$, respectively).

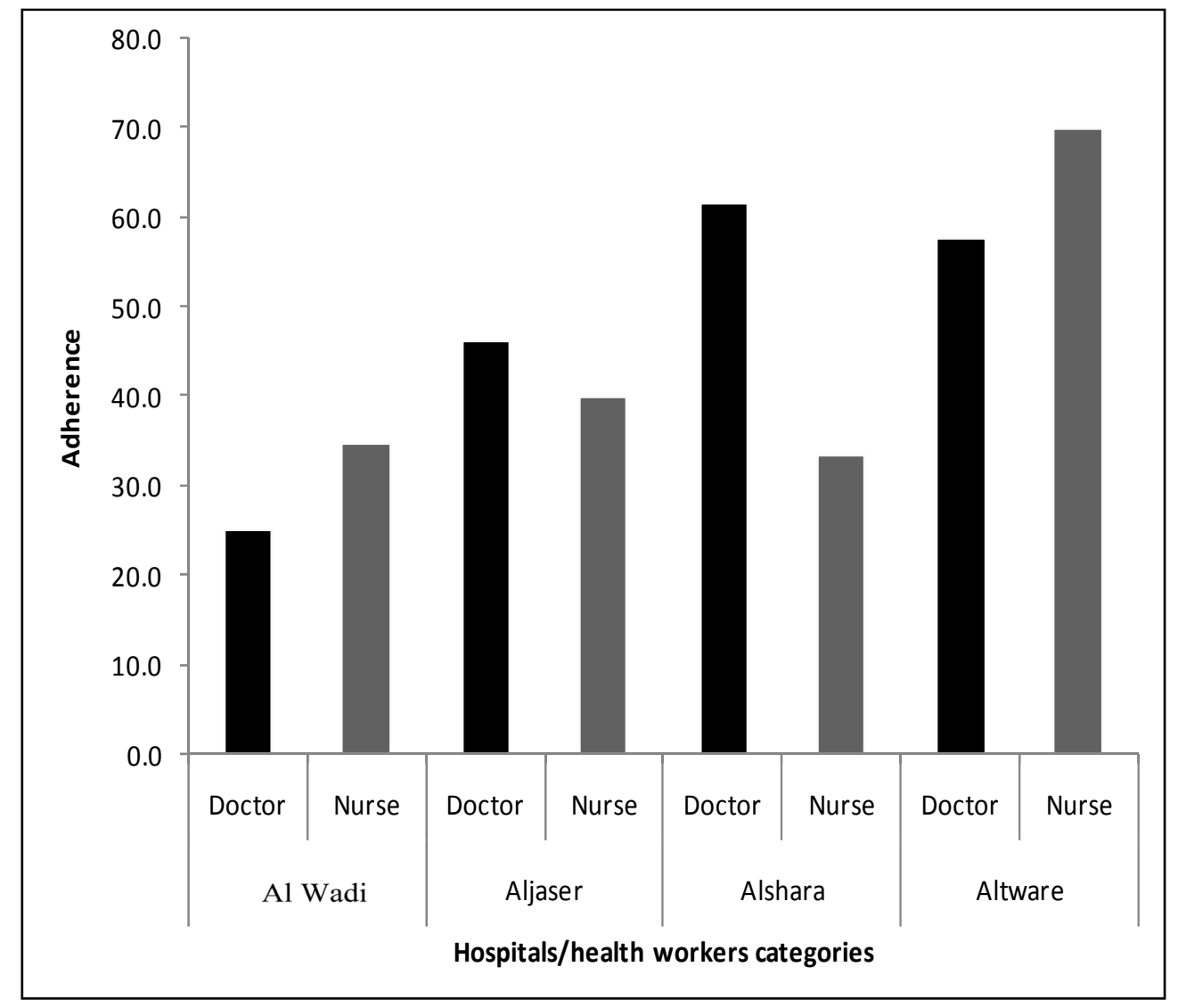

Figure 2. Hand hygiene adherence by healthcare worker category.

Doctors were more adhered to hand hygiene than nurses at Alshara and Aljaser hospitals. At Alshara Hospital, the percentage of doctors who were adhered to hand hygiene was $61.8 \%$, compared to $33.6 \%$ of nurses. At Aljaser Hospital, the percentage of doctors who were adhered to hand hygiene was $46.2 \%$, compared to $40 \%$ of nurses.

Table 6 shows a comparison of hand hygiene adherence between male and female doctors. Adherence to hand hygiene was lower in male doctors than female doctors, and the difference was statistically significant. Among nurses, female nurses were more adhered to hand hygiene than male nurses, but the difference was not significant. 
Hand hygiene adherence with the "Five Moments for Hand Hygiene" is summarized in Figure 3. Moments 4 and 5 recorded the highest adherence at $87.9 \%$ and $85.9 \%$ respectively, whereas moments 1 and 2 recorded the lowest adherence, under $50 \%$. Moment 3 recorded an adherence rate of $40.2 \%$. The high hand hygiene adherence observed after body fluid exposure risk was $87.9 \%$.

Table 6

Hand Hygiene Adherence Among Healthcare Worker Category by Gender

\begin{tabular}{|c|c|c|c|c|c|c|c|c|c|}
\hline \multicolumn{2}{|c|}{$\begin{array}{l}\text { Healthcare worker } \\
\text { category }\end{array}$} & \multirow{3}{*}{$\begin{array}{l}\text { Hand hygiene } \\
\text { opportunities }\end{array}$} & \multirow{3}{*}{$\begin{array}{l}\begin{array}{l}\text { Hand } \\
\text { hygiene } \\
\text { actions }\end{array} \\
153 \\
82\end{array}$} & \multirow{3}{*}{$\begin{array}{l}\begin{array}{l}\text { Percent } \\
\text { adherence }\end{array} \\
(\%)\end{array}$} & \multirow{3}{*}{$\begin{array}{l}\begin{array}{l}\text { Average } \\
\text { adherence }\end{array} \\
39.5 \\
60.0\end{array}$} & \multirow{3}{*}{$\begin{array}{l}\text { Lower 95\% } \\
\text { confidence } \\
\text { interval }\end{array}$} & \multirow{3}{*}{$\begin{array}{l}\text { Upper 95\% } \\
\text { confides } \\
\text { interval } \\
44.2 \\
73.4\end{array}$} & \multirow{3}{*}{$\begin{array}{l}\text { T value } \\
2.484\end{array}$} & \multirow{3}{*}{$\begin{array}{c}\mathrm{P} \text { value } \\
0.015^{*}\end{array}$} \\
\hline \multirow{2}{*}{ Doctor } & Male & & & & & & & & \\
\hline & Female & & & & & & & & \\
\hline \multirow{2}{*}{ Nurse } & Male & 220 & 81 & 36.8 & 42.7 & 30.7 & 43.4 & \multirow{2}{*}{0.800} & \multirow{2}{*}{$0.425(\mathrm{~ns})$} \\
\hline & Female & 480 & 233 & 48.5 & 47.9 & 44.1 & 53.0 & & \\
\hline Total & & 1,215 & 549 & 45.2 & 45.5 & 41.6 & 49.9 & & \\
\hline
\end{tabular}

Note. ${ }^{*}$ Significant at level $0.05 ; \mathrm{ns}=$ not significant.

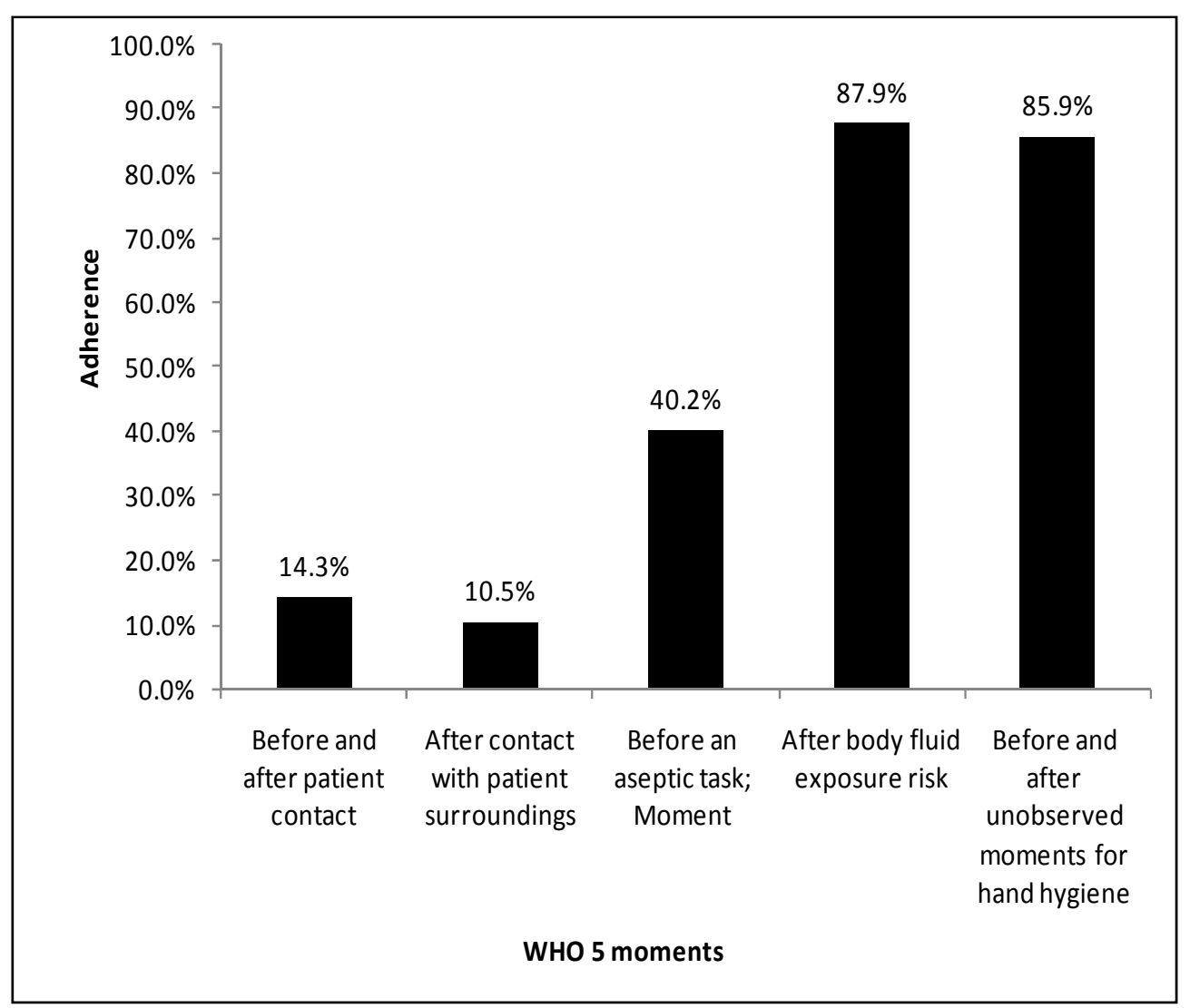

Figure 3. Hand hygiene adherence by the WHO 5 moments of total study population.

Of the 1,215 opportunities at the four pooled hospitals, 549 (45.2\%) were adhered. AHR at 425 (77.4\%) was the favored method used for hand hygiene at the four hospitals and it was used highly at Alshara and Altware hospitals. Washing with soap and water was favored by only 46 (8.4\%), and was highest at Al Wadi Hospital (see Figures 4 and 5). 


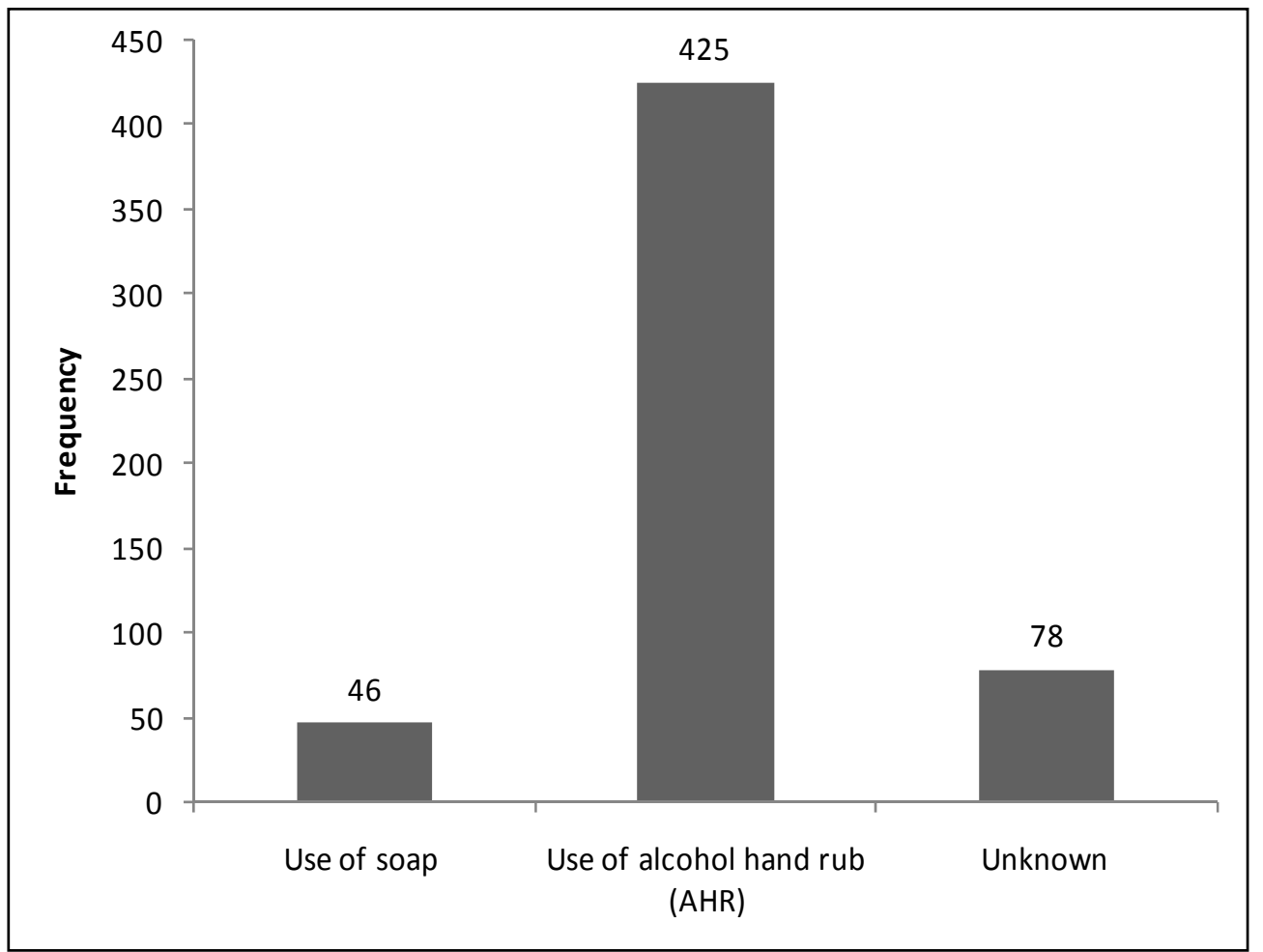

Figure 4. Use of alcohol hand rub (AHR), use of soap, and other actions by HCWs, Mina hospitals, Hajj $1433 \mathrm{H}$.

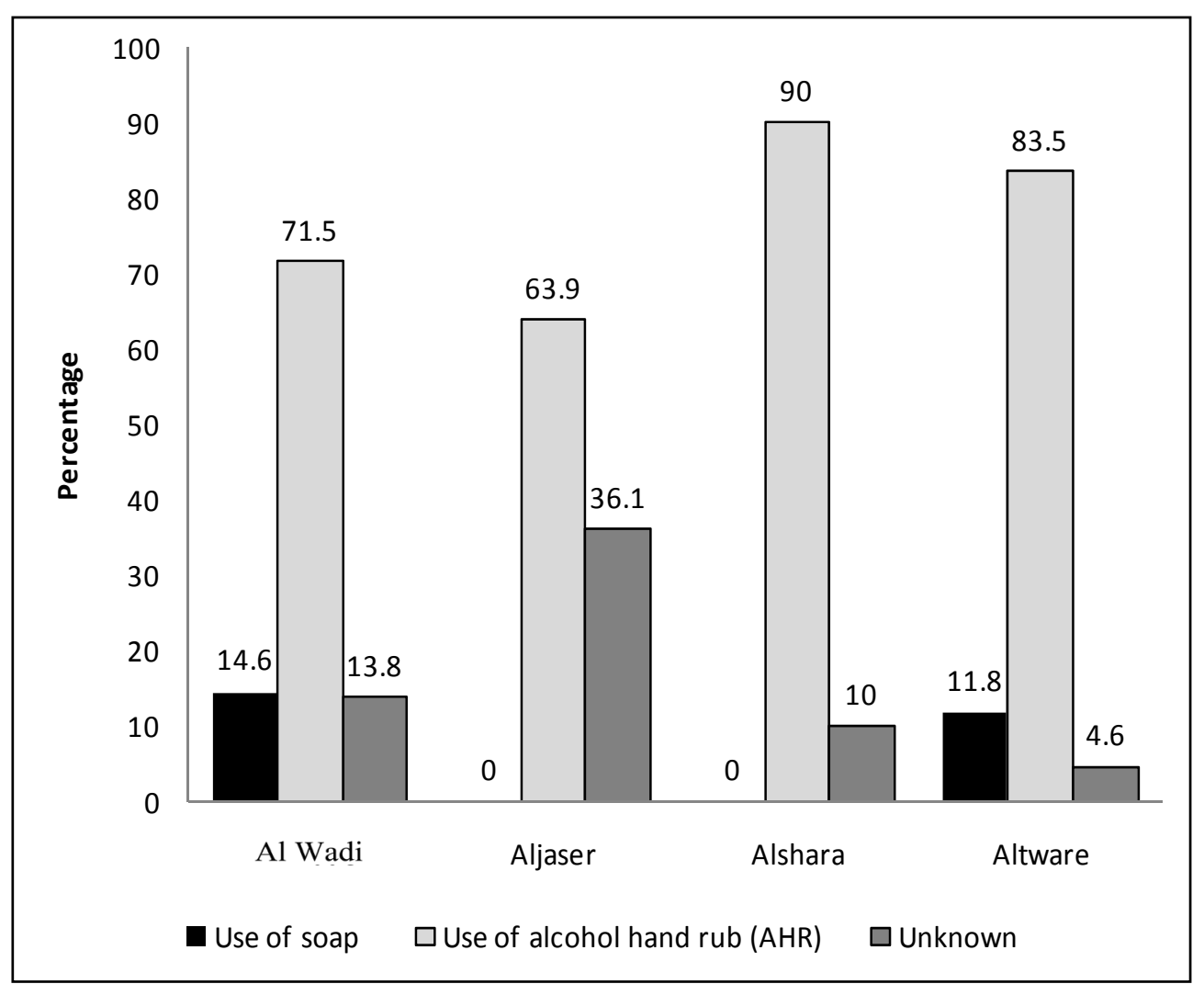

Figure 5. Use of alcohol hand rub (AHR), use of soap, and other actions by HCWs, Mina hospitals, Hajj $1433 \mathrm{H}$. 


\section{Discussion}

Infection control principles such as hand washing and isolation are relatively simple concepts for control and prevention of nosocomial infections. Awareness of the principle of nosocomial infection surveillance, prevention, and control is important and should be the goal for all HCWs.

Hand washing is the simplest practice that has been shown conclusively to decrease nosocomial infection (Centers for Disease Control, 1992).

The research question was to what extent doctors and nurses at emergency departments of the four Mina hospitals adhere to the "WHO 5 Moments" protocol during Hajj season 2012. The results showed that the number of doctors and nurses at the emergency departments of the four Mina hospitals adhered to the 5 Moments protocol was $45.5 \%$, which was lower than a previous study conducted at Hera General Hospital in Makkah city from 2009 to 2010 , which reported a compliance rate of $50.3 \%$. The study mentioned that the reason for poor compliance was mainly the rapid turnover of patients (Bukhari et al., 2011).

On the other hand, the study's compliance rate is higher than a previously reported international rate of 38.7\% (World Health Organization, 2006). However, the results are higher than a local study conducted in Riyadh by the Field Epidemiology Training Program at Prince Salman General Hospital and Al-Eman General Hospital, where the rate of hand hygiene compliance was $17.9 \%$. Another study conducted at Al-Qassem University showed a compliance rate of $17 \%$ (Bukhari et al., 2011), and study conducted at Makkah city hospital during 2006 reported a rate of 40\% (Asare, Enweronu-Laryea, \& Newman, 2009). The result means that the practice of hand hygiene is better than other study practice, but, it is below $50 \%$ and we need to improve it.

Altware Hospital recorded the highest adherence to hand hygiene while Al Wadi Hospital recorded the lowest. Adherence was less than 50\% in all hospitals, except for Altware Hospital which was over $50 \%$.

The results showed that adherence rate significantly differed among hospitals $(p<0.001)$. That lower rate of adherence was at $\mathrm{Al}$ Wadi Hospital ( $0 \%$ to $19 \%)$ and high rate was at Altware Hospital ( $80 \%$ to $100 \%)$.

It is believed that factors explaining why one hospital is different from another in terms of hand hygiene practices include inter-hospital differences in healthcare staff perceptions of institutional support, autonomy, interdisciplinary collaboration, organizational behavior, and hospital culture (Creedon, 2008). In the study, the difference in facility and availability of it, different workload, difference in number of staff, difference of institutional support and hospital culture, which we believe are the factors explaining the difference of rate of compliance.

When observing the different facilities available for hand hygiene at the emergency rooms of the studied hospitals, we found out that Al Wadi Hospital had only four sinks and the AHR was not available at most parts of the department, which explained the low compliance rate. On the other hand, Altware Hospital had six sinks and the AHR was available at every part of the department.

This difference in hand hygiene compliance rate for the benefit of Altware Hospital was also due to the use of AHR as an alternative to hand washing with water and soap, and the availability and easy access to hand hygiene materials at that hospital (Madani et al., 2006).

The study revealed that, overall, compliance was not much different between doctors and nurses, which was different from the findings of other studies that indicated that doctors had lower compliance (World Health Organization, 2006), while being a nurse was a predictor to good compliance. However, on closer inspection, 
doctors at the studied hospitals were more careful when dealing with patients in performing hand hygiene than nurses, who mostly wore gloves throughout the shift.

In the study, doctors and nurses who consistently wore gloves did not wash their hands after and before wearing gloves. Use of one glove was more frequent before and after certain activities, such as before and after touching patient and before and after septic task. The use of gloves gives HCWs a false sense of security, leading them to neglect hand washing. Such lapses are dangerous, because hands can be contaminated through leaks in gloves or when gloves are removed (World Health Organization, 2006).

We found that there was a significant difference between male and female doctors regarding hand hygiene adherence, that such female doctors were more compliant than male doctors. This has been documented in other studies, which reported that males tend to be less compliant to hand hygiene practices (World Health Organization, 2006). However, the study also found that there was no difference in compliance rate between male and female nurses.

The moment after body fluid exposure risk and before and after unobserved moments for hand hygiene recorded the highest adherence at $87.9 \%$ and $85.9 \%$ respectively. On the other hand, the recorded adherence rate of moment before an aseptic task was $40.2 \%$. This indicated that the HCWs were keen to wash their hands after and before activities perceived as having a high risk of cross-contamination or cross infection to them (World Health Organization, 2006).

On the other hand, moments before and after contact with patient recorded the lowest adherence rate, which was lower than $50 \%$. This could be attributed to lack of knowledge of the importance of hand washing before and after touching patient or hand hygiene guidelines, wearing of gloves, forgetfulness, patient needs perceived as priority, high workload, and understaffing (World Health Organization, 2006; Asare et al., 2009).

The study showed that hand antiseptic (AHR) was the most favoured type used by participants in the study for hand hygiene, more often than water and soap. This means that HCWs prefer to use AHR, since they require less time, act faster, and irritate hands less often than soap. Other contributory reasons may be the fact that sinks were inadequate in number or inconveniently located, and in some hospitals, there were no sinks and no soap or paper towels. In this study, the hand hygiene compliance in four hospitals was mainly due to the use of AHR as an alternative to hand washing with water and soap, which documents its role in increasing hand hygiene compliance (Madani et al., 2006).

The compliance rate for hand hygiene has been reported as low in many studies. In a study conducted at an intensive care unit in Ghana in 2009, the reported compliance rate was $12.2 \%$ (Asare et al., 2009).

\section{Conclusions}

The compliance rate of hand hygiene was $45.5 \%$, but we are unable to evaluate this rate critically due to absence of a national value for comparison purposes. There were no difference of hand hygiene compliance between doctors and nurses at the four hospital emergency departments. Also, we found no difference of hand hygiene compliance rate by gender except between doctors, where females were found to be more compliant.

There was a difference between the hand hygiene facilities available at the four hospitals, which was reflected in the compliance rate. There was higher compliance where there were available hand hygiene facilities. Availability and use of AHR had an excellent effect on improving hand hygiene compliance rate. 
We conclude that improved hand hygiene facilities and equipment at hospitals are imperative for improvement of hand hygiene. Furthermore, a multidisciplinary approach is required, with reinforcement and education to improve HCWs' adherence to hand hygiene.

\section{Recommendations}

(1) Health education about the importance of hand washing in the hospital settings should be improved, educating HCWs about proper techniques of hand washing in the run-up to the Hajj season;

(2) The proper facilities for hand washing should be provided at every hospital department according to number of beds, making them easily accessible;

(3) Efforts to improve hand washing practice should be multifaceted and should include continuing education and feedback to staff on behavior or infection surveillance data;

(4) Medical and administrative staff should be involved in the planning and implementation of strategies to improve the compliance of hand washing during Hajj seasons;

(5) Continuous observation of the HCWs should be done by infection control departments to improve the compliance and the techniques of hand washing;

(6) Audit of the incidence of infection, feedback of these infection rates to clinical staff, and continuous infection control education programs should be provided;

(7) There shoule be one infection control nurse for every 250 beds, and infection control audit for evaluating clinical practice;

(8) Registering government hospital in Saudi Arabia to make national compliance rates, which help to identify the reasons of non-compliance, and to design interventions to raise compliance.

\section{References}

Anwar, M. A., Rabbi, S., Masroor, M., Majeed, F., Andrades, M., \& Baqi, S. (2009). Self-reported practices of hand hygiene among the trainees of a teaching hospital in a resource limited country. Journal of the Pakistan Medical Association, 59(9), 631-634.

Asare, A., Enweronu-Laryea, C. C., \& Newman, M. J. (2009). Hand hygiene practices in a neonatal intensive care unit in Ghana. $J$ Infect Dev Ctries, 3(5), 352-356.

Bartzokas, C. A., Williams, E. E., \& Slade, P. D. (1995). A psychological approach to hospital-acquired infections: Studies in health and human sciences. London: Edward Mellen.

Basurrah, M. M. A., \& Madani, T. A. (2006). Handwashing and gloving practice among health care workers in medical and surgical wards in a tertiary care centre in Riyadh, Saudi Arabia. Scand J Infect Dis, 38(8), 620-624.

Bukhari, S. Z., Hussain, W. M., Banjar, A., Almaimani, W. H., Karima, T. M., \& Fatani, M. I. (2011). Hand hygiene compliance rate among healthcare professionals. Saudi Med J, 32(5), 515-519.

Centers for Disease Control. (1992). Public health focus: Surveillance, prevention, and control of nosocomial infections. MMWR, 41(42), 783-787.

Centers for Disease Control. (1988). Update: Universal precautions for prevention of transmission of human immunodeficiency virus, hepatitis B virus, and other bloodborne pathogens in health-care settings. $M M W R, 37(24), 378-388$.

Creedon, S. A. (2008). Hand hygiene compliance: Exploring variations in practice between hospitals. Nurs Times, 104(49), 32-35.

Emmerson, A. M., Enstone, J. E., \& Griffin, M. (1996). The second national prevalence survey of infection in hospitals. $J$ Hosp Infection, 32, 175-190.

Haley, R. W., Culver, D. H., White, J. W., Morgan, W. M., Emori, T. G., Munn, V. P., \& Hooton, T. M. (1985). The efficacy of infection surveillance and control programs in preventing nosocomial infections in U.S. hospitals. Am J Epidemiol, 121(2), 182-205.

Larson, E., MCGinely, K. J., Grove, G. L., Leyden, J. J., \& Talbot, G. H. (1986). Physiological, microbiologic, and seasonal effects of handwashing on the skin of health care personnel. Am J Infect control, 14(2), 51-59. 
Larson, L., Aiello, A., \& Cimiotti, J. P. (2004). Assessing nurses' hand hygiene practices by direct observation or self-report. Journal of Nursing Measurement, 12(1), 77-85.

Madani, T. A., Albarrak, A. M., Alhazmi, M. A., Alazraqi, T. A., Althaqafi, A. O., \& Ishaq, A. H. (2006). Steady improvement of infection control services in six community hospitals in Makkah following annual audits during Hajj for four consecutive years. BMC Infect Dis, 6, 135 .

Madrazo, M., Dorado, A., Fort, M., Herranz, J. C., Selfa, R. A., Ferradal, I. G., ... Diaz, S. S. (2009). Effectiveness of a training programme to improve hand hygiene compliance in primary healthcare. BMC Public Health, 9, 469.

Rotter, M. L., \& Koller, W. (1991). A European test for the evaluation of the efficacy of procedures for the antiseptic handwash. Hyg Med, 16, 4-12.

Tibballs, J. (1996). Teaching hospital medical staff to handwash. Med J Aust., 164(7), 395-398.

World Health Organization. (2006). WHO guidelines on hand hygiene in health care (advanced draft). Retrieved from http://www.who.int/patientsafety/information_centre/Last_April_versionHH_Guidelines $\% 5 \mathrm{~b} 3 \% 5 \mathrm{~d} . p d f$ ?ua $=1$ 


\section{Appendix A}

Questionnaire for observation of facilities for hand hygiene

SRN:

Name of ward:

I: Available facilities:

Do the taps have handles? Y/N

Do the taps have foot controls? $\mathrm{Y} / \mathrm{N}$

Do the taps have automatic shut off? Y/N

Which one available:

Bar soap?

Liquid soap?

Chlorhexidine $4 \%$ ?

Are there paper towels for hand drying? Y/N

Are the hand-drying materials placed near the sink? Y/N

\section{Appendix B}

\section{The Hand Hygiene Observation Tool (HHOT)}

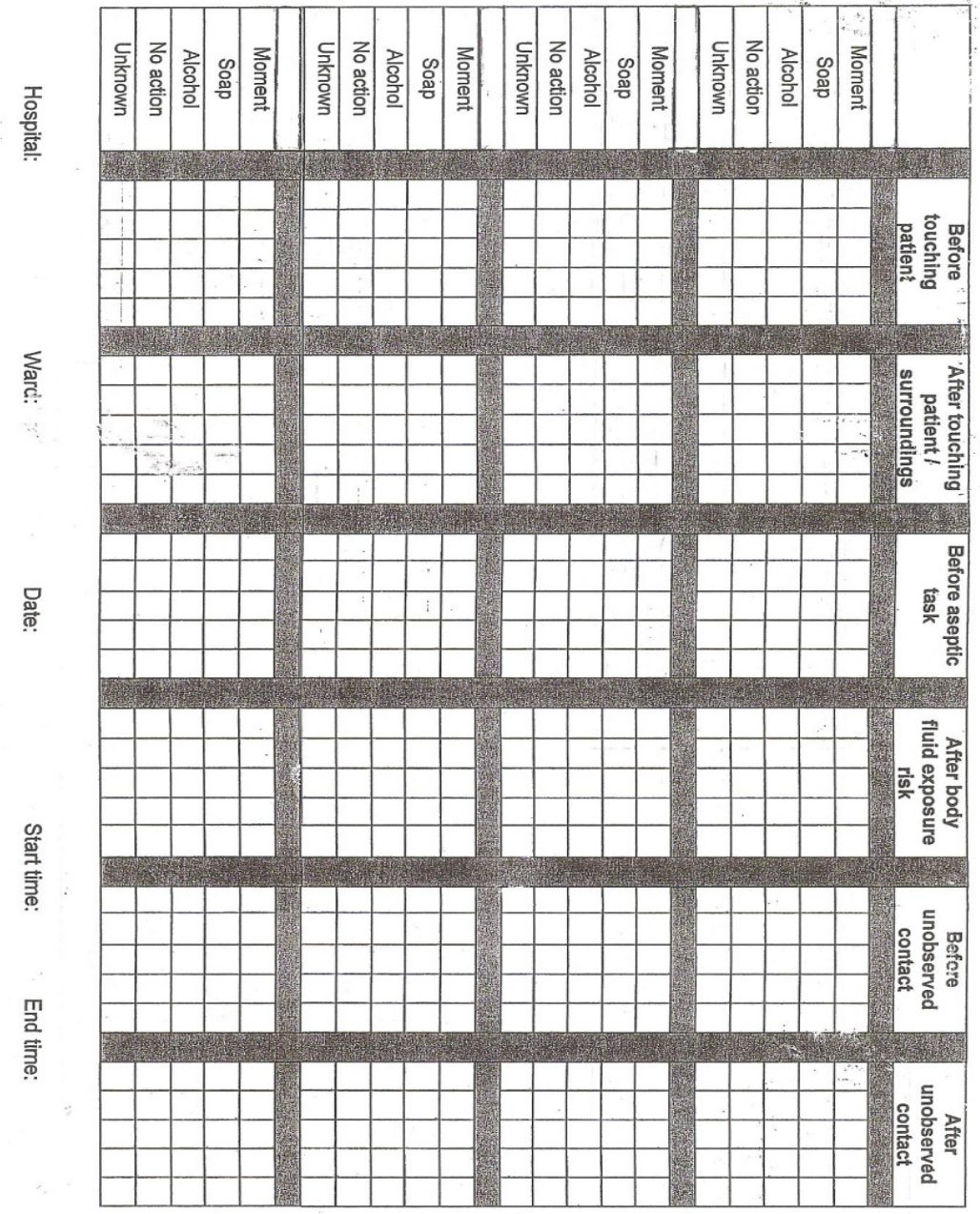

